\title{
Do cartoons trigger an influence on children's altruism?
}

\author{
Claudiu Lulciuc ${ }^{\bullet}$, Mihaela Minulescu`, Laurențiu Maricuțoiu•
}

\begin{abstract}
The present study evaluated children's prosocial behavior $(M=7.39, S D=0.93)$ (i.e., specific altruism) under the influence of three types of cartoons (neutral, prosocial, or antisocial). Subjects $(N=140)$ were randomized and exposed to treatment with pre- and post-intervention measurements. The results didn't confirm the hypothesis that children who will watch prosocial cartoons will have increased altruism proving a higher volume of donations. The second hypothesis regarding the inhibitory effect of antisocial cartoons on altruism by decreasing the volume of donations was not confirmed either. No significant gender effects were recorded. No significant general age effect was found either, however, we found that donations tend to increase with age, a statistically significant effect being recorded for children age 8 years old compared to those of 6 years old. The implications of the statistical data are discussed together with the possibility of registering a "moral licensing" effect.
\end{abstract}

Keywords: cartoon, children, prosocial behavior, altruism, media

Improving the quality of life, finding the positive feature for human life and continuous research for the development of prosocial behavior is a topic of great interest nowadays and it is indeed a great need (Seligman \& Csikszentmihalyi, 2000; Beilin, 2013). Positive psychology research manages to shift the balance in the proper direction by giving great importance to positive subjective experience, positive traits, and other aspects of life and human psychology in order to improve individuals' life. Indeed, just as Seligman was saying, we need "more than fixing what is wrong with them. It is about identifying and nurturing their strongest qualities" (Seligman \& Csikszentmihaly, 2000, p. 6). We believe that this concept needs to be applied in relation to media, meaning not just to identify what is negative in media but to identify and disseminate what is good and helpful for human psychological development, this approach being in concordance with Seligman \& Csikszentmihalyi, who were hoping that our century "will see a science and profession that will come to understand and build the factors that allow individuals, communities, and societies to flourish" (Seligman \& Csikzentmihalyi, 200, p. 5). This is necessary to

\footnotetext{
- PhD student, Doctoral School of Psychology, West University of Timișoara, Romania, claudiu.lulciuc83@e-uvt.ro

- PhD, Professor at the Faculty of Communication and Public Relation, National University of Political Studies and Public Administration, Romania, The Romanian Association of Analytical Psychology, mirunaminulescu@gmail.com

- PhD, Associate Professor, Department of Psychology, West University of Timișoara, Romania, laurentiu.maricutoiu@e-uvt.ro
} 
develop prosocial behaviors, and we need to focus not just on the factors that determine antisocial behavior as this is just "one side of the coin".

The motivation for prosocial acts can vary considerably, and we need to know what are the factors that predetermine prosocial behavior. For this present study, we will distinguish between prosocial behavior (generally speaking) and altruism (a certain type of prosocial behavior) in the terms of Eisenber \& Mussen (1989). Generally, a prosocial behavior "is an act designed to help or benefit one or more people" (Eisenber \& Mussen 1989, p. 3) and can often be motivated from the outside (reward, approval from others, etc.). On the other side, "altruism" is "a voluntary action intended for the benefit of another person, being intrinsically motivated - namely, an act motivated by internal motives such as concern or sympathy for others or internal values and self-reward to the detriment of personal gain" (Ibidem). This definition is following Carlo's research where he also regards altruism as a behavior manifested without rewards expectations for the benefit of others, which is internally motivated (Carlo et al., 2010; Carlo et al. 2007).

Although it is often difficult to identify the motivation behind the prosocial act, Eisenberg (1983) suggests that more attention should be paid to empathy and its development, with more researchers agreeing that empathy is indeed an important factor for prosocial behavior, including altruistic behavior. Sometimes empathy is responsible for acts of great sacrifices (Spinrad \& Eisenberg, 2009; Batson et al., 1981; Hoffman, 1982). The development of empathy for children, along with other methods, can be done through a real model (e.g., parent) or virtual (T.V.). Various studies have captured this fact where the role model for developing help was either an adult (Yarrow et al., 1973) or a virtual character (Coastes et al., 1976; Forge \& Phemister, 1987), including prosocial acts such as a donation (Teachman \& Orme, 1981). Childhood (8-11 years) remains the age sector with the most significant influence on prosocial behavior (Foulkes et al., 2018).

The prosocial behavior of interest of the present study, altruism manifested through the act of donation, is known to be an act devoid of external reward motivation, an intentional, voluntary behavior (Eisenberg et al., 2015; Underwood \& Moore, 1982). Based on these facts, in this study, the motivation for donation was presented as an aid given to a boy who has a health issue and, for this reason, he can't be with the class. The money that they will donate will be used to buy him some sweet treats in order to ease his recovery time. To keep an act of donation as internal motivation, the act should not be rewarded in any form. Children need to manifest their will freely for the behavior to be registered as altruistic and not in terms of gain and loss. For this present study, the act of donation received no promise of future reward. It has been presented just in terms of helping a child.

Age effects on displaying prosocial behavior

After an analysis of different studies Wilson (2008) underlines the fact that children's empathy and altruism seems to be higher among those children of higher age. Zarbatany et al. (1985) also captures the same effects regarding generosity, children from 5 th grade are more generous than thouse from 1st grad. Skarin and Moely (1976) also recorded a 
higher level of altruistic for ages 10-12 years compared with those of 7-9 years, and similar results have been found by other researchers (Peterson, 1983, Evans et al., 2013, Brocas et al. 2017). Fehr et al. (2011) found that starting age 8 years old, children tend to become more altruistic. Kogut (2012) also analyzed altruistic behavior and satisfaction among children and recording similar results. Because age tends to influence children's altruism we have taken this variable into consideration as it can affect the results.

Gender effects

In the case of children, altruistic behavior has a certain plasticity (Lozada et al., 2014), is subject to different factors (Madsen et al. 2010) and can be learned or improved even as a result of trauma (Staub \& Vollhardt, 2008). Various research studies reported gender differences regarding children altruism. Skarin and Moely (1976) reported that girls obtained higher altruism scores than boys, but also that among age 7-9 years old, girls seemed to be low in altruism. Angerer et al. (2015) found that altruism seems to increase with age and that girls have higher values than boys. Also children that have older brothers seem to be subjects of less altruistic behaviors. The act of manifesting more prosocial behaviors among girls compared to boys could be due to the fact that girls tend to place more importance on prosocial values than boys (Baillargeon et al., 2011; Betuel \& Johnson, 2004). These differences are taken into consideration to manifest under present research design.

\section{The present research}

This study uses Teachman and Orme's (1981) model to measure children's generosity prosocial behavior. The method chosen to measure the prosocial behavior of generosity was already used in similar measurement procedure by Rushton $(1975,1976)$ and others (Rushton \& Teachman, 1978, Rusthon \& Wiener, 1975). The primary interest of this study is to highlight the role that the prosocial cartoons can play in the prosocial development of children (altruism) and also to observe if cartoons have an inhibition effect (for altruism), as a result of watching the cartoons with antisocial content. The major difference is given by the target group of children, where, unlike Teachman and Orme (1981), the subjects' age was 8-10 years old. For this present study, we have included children between 6-9 years, as it is known that at this age children can already distinguish between fiction (virtual) and reality (Bjorkqvi \& Osterman, 2001, Downs 1990, Weaver et al., 2011). Also, several experimental studies have included same age group to record different effects of cartoons (Hapkiewicz \& Roden, 1971, Frydman 1999, Ellis \& Sekyra, 1972 ).

The interest of this present study is given by means of the need to observe possible influences on psychological health and behavioral implications for children who watch different types of cartoons. This experiment has an improved method of measuring the prosocial act (altruism) given the fact that the donation is made in an empty bowl - the act of donation not being stimulated a priori by the presence of golden coins (as in the Teachman and Orme experiment where there were already 12 coins in the donation 
bowl). The act of generosity in the present experiment is measured in isolation, possible mediating factors that can be anticipated being eliminated by design. The design of this study, unlike Teachman and Orme, is built to measure children's prosocial behavior altruism as a result of watching a cartoon where prosocial behavior is presented as intrinsically good. This fact is different from the study of Teachman and Orme, where children were exposed to a cartoon whose morality, prosocial act, is associated with religious teachings. In his study, Teachman and Orme used an episode from Davy \& Goliath where moral behavior is taught and strengthened in the light of religious teachings, this cartoons presenting religious moral tales. The 2 hypotheses of the present study are:

H1: Children exposed to prosocial cartoons will experience increased altruism, recording a higher volume of donations than those who watched antisocial cartoons.

$\mathrm{H} 2$ : Children exposed to antisocial cartoons will register lower altruism, recording a smaller volume of donations than those who watched cartoons with a prosocial character.

\section{Method}

\section{Participants}

Subjects $(\mathrm{N}=140)$ were children enrolled in primary school (age 6 - 9 years old) from Cluj city (Romania). The children's average age was 7.39 years $(S D=0.93)$, in a ratio of 44.3\% girls and 55.7\% boys. According to the self-report data collected from the questionnaire and the consent given by the parents, the economic status of the study participants is mostly classified as "good", recording a percentage of $80.0 \%$, and a percentage of $15.7 \%$ of families declared to have a "very good" economic status.

The subjects are from the same school in Cluj, the experiment taking place in both educational locations of the institution. The children's age distribution was as follows: $19.3 \%$ of students age 6 years old, $35 \%$ of students 7 years old, $33.5 \%$ of students 8 years old, and $12.1 \%$ of students were 9 years old. Children corresponding these ages are enrolled in preschool classes, both first and second grades of this preschool. The distribution by school classes was $37.1 \%$ students in the preschool class (52 students), $32.9 \%$ students in 1 st grade (46 students), and $30.0 \%$ students in the 2 nd grade (42 students). All data are displayed in Table 1 . The distribution of subjects by age indicated no significant differences between groups $[\mathrm{F}(1,139)=1,583, p=0.209]$. Also, no significant difference between groups was identified based on subjects $[\chi 2(2, N=40)=$ $0.166, p=0.920]$. Prior to applying the experiments, parental consent was requested for each child included in the study, parents giving their consent within 1 week before the study was performed. 
Table 1 - Demographic characteristics of the study sample

\begin{tabular}{lccc}
\hline & Variable & Frequency (\%) & M (S.D.) \\
\hline Gender & Girls & $62(44,3 \%)$ &, $56(, 49)$ \\
& Boys & $78(55,7 \%)$ &
\end{tabular}

Class

$$
\begin{array}{cl}
\text { Preparatory class } & 52(37,1 \%) \\
1^{\text {st }} \text { class } & 46(32,9 \%) \\
2^{\text {nd }} \text { class } & 42(30,0 \%)
\end{array}
$$

Child age

$\begin{array}{ll}6 \text { years } & 27(19,3 \%) \\ 7 \text { years } & 49(35,0 \%) \\ 8 \text { years } & 47(33,5 \%) \\ 9 \text { years } & 17(12,1 \%)\end{array}$

Daily screen time dedicated to cartoons

$\begin{array}{cc}0-15 \mathrm{~min} & 32(22,9 \%) \\ 15-30 \mathrm{~min} & 33(23,6 \%) \\ 30 \mathrm{~min}-1 \mathrm{~h} & 45(32,1 \%) \\ 1 \mathrm{~h}-1 \mathrm{~h} 30 \mathrm{~min} & 17(12,1 \%) \\ \text { 1h } 30 \mathrm{~min}-2 \mathrm{~h} & 5(3,6 \%) \\ 2 \mathrm{~h}-3 \mathrm{~h} & 6(5,3 \%) \\ >3 \mathrm{~h} & 1(, 7 \%)\end{array}$

Parents financial status*

Low-income family

$$
0(0 \%)
$$

Middle-income family

High-income family $22(15,7 \%)$

* Missing 6 entries for financial status (4,3\%)

\section{Procedure}

To apply the study, the approval of the school management was obtained together with the parent's consent for each child. For the present experiment, 154 (92.3\%) parents expressed their agreement to participate in the experiment, 13 parents $(7.7 \%)$ refusing to give their consent. Out of the total of 154 subjects for whom the agreement was offered, 14 subjects $(8.3 \%$ of the total number of subjects) were unable to participate in the experiment due to different health problems. Because of these health problems (i.e. varicella virus) children had to stay home. Thus the study included a final number of 140 subjects. The experiment took place at the end of March (2019), 1 week after the parents' consent and lasted for 4 school days, determined by the school time intervals. 
The experiment stages were divided into 5 sequences for each session, keeping the same intervention scheme throughout all the sessions. The students were randomized and led to the experimental room where the intervention took place. On average, 11 children participated in each session, and the duration of each session was approximately 45 minutes.

The evaluator made introduction to the study by presenting the fact that they will participate in a puzzle game type "find the pair". For this, each child was placed in front of a tablet with a screen size between 8-10 inches, where the children were to play a game in which they had to find the pair of each fruit under one of the 16 cards (8 pairs of fruits). The activity was used to distract children from the interest assessment of the experiment.

The experiment of interest aimed at evaluating altruism by measuring the donation that each child was willing to make after watching a cartoon (neutral vs. prosocial vs. antisocial). For this, the subjects were offered a number of 10 gold coins, money with which they finally had the opportunity to get a surprise prize. They were informed that if they have more money they will have the opportunity to get a special prize. Before moving on to the "find the pair" game, the children were informed that a little boy named Mihail would have really wanted to participate in order to win a special prize, but due to health reasons, he could not be present. A picture of Mihail was shown to the children and placed in front of their eyes in a photo frame throughout the experiment (this was done in order to help children empathize with Mihail). Mihail's appearance was naturalistic, presenting a school boy, a child aged about 8-9 years, relatively serious, who looks ahead, in a portrait-type picture, on his shoulders the straps of a backpack being visible. The children were presented with the opportunity to make a donation for Mihail, as per their own will. The donation was to be made out of the sight of the other children in order to not be constrained by peer pressure. In the arrangement of the experimental room was placed a panel that masks the act of donation, the donation being made behind a panel of sufficient size to mask the entire donation process.

The pre-test evaluation consisted of recording each donation made by the children. For this, the subjects were directed to go through the donation booth, one by one, behind the panel, where Mihail's photo was placed on the desk near the donation bowl. An empty bowl was at the disposition of the children to donate as much money as they wanted, withholding whatever sum of money they personally desired. The projection screen (similar to a $1.6 \mathrm{~m}$ white opaque panel) was used to protect them from the pressure of the other children's eyes at the specific moment of donation. Throughout the experiment, the children were forbidden to talk to eachother, in order to eliminate any possible influence upon the act of donation. After passing the table where Mihail's picture and the donation bowl were, each child returned to his or her place to play the promised game on the tablet.

Experimental exposure was presented as a recreational moment before starting a new "find the pair" game on the tablet. Each group was exposed to a specific cartoon (neutral, prosocial or antisocial). The cartoon presentation was done with the help of a video 
projector and external speakers, such that both the image and the atmosphere of the cartoon (through the sound) would be pleasant, the attention being focused exclusively on the cartoon.

The post-test evaluation consisted of another session of donation in the same experimental design, children being motivated to win another special prize, which will also remain secret at that specific moment. Subjects were offered another set of 10 gold coins, reminding them that they have the opportunity to make a donation for Mihail so that he too may enjoy a prize. The donation was to be made under the same conditions as in the first instance, away from the eyes of peers through a separator, quietly and voluntarily, with the freedom to donate from 0 to 10 golden coins. Following the donation, the children were offered the opportunity to play a new game, "find the pair", as a reward for their collaboration.

The end of the session included congratulating the children for their collaboration and for the donation made to Mihail and assuring them that they will receive the award in a short time,. The children were taken to their classes. All children ended the experimental session with great enthusiasm, the children being out of any negative afect due to the experimental design. At the end of all the experimental sessions, the children were offered the promised prize within the entire team of each class. The prizes (special chocolate) were given only at the end of all the sessions, motivated by the possibility of losing the interest of other subjects if it would have been given before that specific time.

\section{Research design}

The present research has an experimental design and aimed at measuring prosocial behavior - altruism as a result of watching cartoons. Two hypotheses were formulated, which directly target prosocial behavior, the "altruism" component, under the influence of cartoons, with the expectation that the volume of generosity will either increase or decrease. The sampling was multistage random (cluster type randomization) the subjects being selected from the educational institution from all preparatory classes, 1st classes and 2nd classes, being made a subsequent division according to gender (b / f), with distribution within the 3 experimental groups (neutral, prosocial, antisocial). Thus, the number of subjects of each experimental group was controlled, the groups remaining in balance for gender and the total number of subjects (Fig. 1).

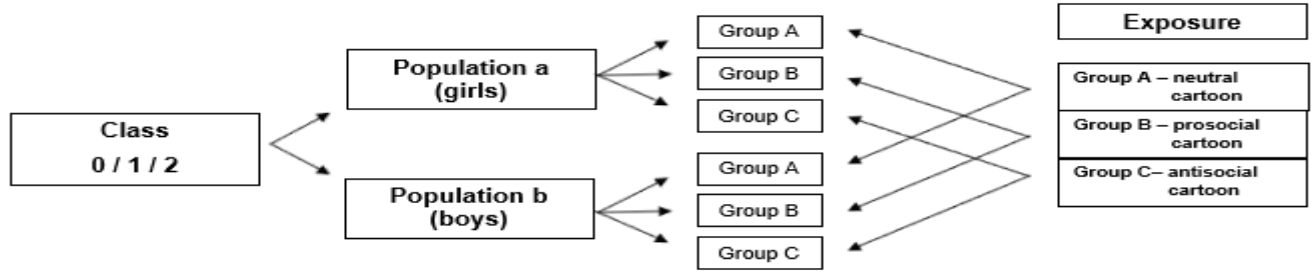

Fig. 1. Randomization process

The independent variable is the cartoon type (neutral vs. prosocial vs. antisocial). The average duration of the cartoons used in this experiment was 5 minutes and 23 seconds. The neutral group was exposed to the cartoon called "Alex in the sea" where the main 
character, Alex, a child, discovers the underwater world and every time he meets new creatures, he makes a picture that he develops and analyzes later. The episode presented is a mix of 2 episodes in which Alex met a dolphin and an octopus separately. The duration of the cartoon is 5 minutes and 16 seconds.

The prosocial cartoon used in the experiment was "Kit and Keit: The Big Bouquet" where the 2 main characters go to a valley full of flowers. There they find a little dinosaur crying because he wants to make a present for his mother for her birthday. Together they start collecting flowers (empathy is present) for the dinosaur's mother (help), which they offer to the little dinosaur (generosity), but they find that they have ruined the valley by collecting them all. Following an explicitly presented morality (moral lesson), he starts picking flowers again, but only as much as he needs (lesson learned). Afterward the bouquet is offered to the mother, and everyone is happy. This cartoon aimed helping as a result of empathy, the characters gathering and offering flowers (generosity) out of selfinterest, to make someone else happy. All the elements presented in this cartoon have a prosocial theme and are important in the act of donation. The total duration of the cartoon was 5 minutes and 19 seconds, and the dialog between cartoon characters was made in the subject's native language.

The antisocial cartoon was from the series of "Woody the Woodpecker", the episode titled "Short in the saddle". The cartoon shows the woodpecker Woody going to the western lands in search of gold. The whole scenario highlights the fight between a bandit and the woody woodpecker for a bag of gold, along the way there are shootings, blows, winning, and temporary loss of the bag of gold by each character. The end surprises the fact that the coveted bag is empty, ending with the specific laughter of the woody woodpecker. The duration of the cartoon is 5 minutes and 33 seconds. This cartoon was selected because it underlines the fight for so considered money and because the characters are determined to win the bag.

Child gender was the second independent variable taken into consideration in order to record different altruistic behavior among children as this variable has the potential to influence the results. Sometimes boys tend to copy cartoon characters' behavior more than girls (Ergun, 2012), but generally, girls tend to record higher scores on altruism than boys (Angerer et al. 2015).

Child age was the third independent variable, different studies recording that altruism increased with age (Evans et al., 2013, Brocas et al. 2017). Israely and Guttmann (1983) also recorded that older children (5th grade) tend to manifest higher altruism than younger ones after watching a puppets show. As it is largely known that this variable can influence the outcome, we have taken it into consideration as an independent variable.

The dependent variable was prosocial behavior-altruism, measured by the volume of donations recorded after watching the cartoon. In order to measure the act of donation, each subject received a number of 10 golden coins having the option to either keep all the money for themselves or donate as per their own will ( 0 - 10 golden coins). The motivation for keeping the money was the surprise gift whose value was considered to 
be in direct relation to the number of golden coins kept: keeping a larger number of golden coins was considered to materialize in a bigger and more beautiful gift. Based on this fact, the children decided whether to donate to Mihail, a boy of their age who was not present because he was sick. In order to make it as realistic as possible a picture of Mihail was posted on a picture frame near the donation bowl. Children had the possibility of either donate or keep al the money for themselves. In order to eliminate any other unknown variable, such as peers' pressure for donating or not, children were asked to remain quiet throughout the experiment, and the donation was made behind the set (panel) specially installed to protect the donor from the eyes of other subjects.

\section{Measures}

The evaluation of the prosocial behavior was performed with the help of 10 golden coins that the children received before each measurement. Children started the session with an introduction to the experimental room and were informed that they would receive some golden coins and, based on the number of golden coins that they will keep, will receive a prize. After this instruction, the case of "Mihail" was introduced and also the possibility of donating for him in order to help him as he is in a special condition (ill), this way making things possible for him to receive also a special gift. After the donation took place, all subjects were given the possibility of playing a game ("find the pair") on tablets, which were displayed for each subject. After all, children have ended the game, the evaluator told them about a surprise that he has for them, a cartoon. Full of joy, children watched the cartoon designed specifically for each experimental group. Immediately after the exposer, the prosocial behavior was measured again, in a new act of donation, after which the session ended with a new game on the tablet (same "find the pair"). Following each donation, the remaining coins were collected, the subjects being assured of the fact that it was noted how many coins they kept for themselves in order to receive their prize. The two donation sessions were separated by an online game via tablets, in which children had the duty to find the pair of fruits presented on the screen.

\section{Data analysis}

Analysis of the data for altruism (a specific component within the prosocial behavior) was performed using repeated measurements of ANOVA. The independent variable was the type of cartoon (neutral Vs. prosocial Vs. antisocial), gender and child age, and the dependent variable was the volume of donations made by each group. Statistical analysis has been performed with the help of the program IBM SPSS Statistics, version 25 . 


\section{Results}

\section{Main analyses}

The volume of donation was measured for each group, results indicating the means of standard deviations of golden coins donated. The means and standard deviations for the initial state (pre-intervention) for the neutral group (boys \& girls) was $M=3.55$ ( $S D=$ $3.62)$, the prosocial group recorded $M=3.64(S D=3.19)$ and the antisocial group recorded $M=5.13(S D=3.61)$, total mean for pre-intervention was $M=4.12(S D=3.54)$. After intervention (post-exposure) the neutral group recorded $M=3.30(S D=3.37)$, the prosocial group recorded $M=3.62(S D=3.00)$ and the antisocial group recorded $M=3$, $52(S D=3.33)$, the total mean for post-intervention stage was $M=3.48(S D=3.22)$. Overall girls manifested a higher altruism then boys recording a mean $M=4.31(S D=$ 3.63) unlike boys mean $M=3.97(S D=3.48)$ in pre-exposure stage. Also after exposure girls recorded a mean $M=3.94(S D=3.48)$ and boys recorded a mean $M=3.12(S D=$ 3.98). Descriptive statistics of donations made in each group and as per child age are presented in table 2 .

Table 2 - Descriptive statistics of donations made in each group and measurement moment

\begin{tabular}{|c|c|c|c|c|c|}
\hline \multirow{3}{*}{$\begin{array}{c}\text { Media } \\
\text { type }\end{array}$} & \multirow{3}{*}{ Children age $(\mathrm{N})$} & \multicolumn{2}{|c|}{ Pre exposure } & \multicolumn{2}{|c|}{ Post-exposure } \\
\hline & & \multicolumn{2}{|c|}{$M(S . D)}$. & \multicolumn{2}{|c|}{$M(S . D)}$. \\
\hline & & Girls & Boys & Girls & Boys \\
\hline \multirow[t]{5}{*}{ Neutral } & 6 years $(\mathrm{N}=12)$ & $1.67(1.86)$ & $3.17(3.54)$ & $1.83(1.83)$ & $1.33(1.51)$ \\
\hline & 7 years $(\mathrm{N}=18)$ & $2.86(3.80)$ & $2.45(2.42)$ & $3.14(3.80)$ & $3.09(2.55)$ \\
\hline & 8 years $(\mathrm{N}=11)$ & $8.00(3.37)$ & $4.57(4.24)$ & $6.25(4.35)$ & $3.86(4.38)$ \\
\hline & 9 years $(\mathrm{N}=6)$ & $5.33(4.51)$ & $3.67(5.51)$ & $4.67(4.73)$ & $4.67(4.62)$ \\
\hline & Total $(\mathrm{N}=47)$ & $3.90(3.91)$ & $3.30(3.45)$ & $3.60(3.68)$ & 3.07 (3.19) \\
\hline \multirow[t]{5}{*}{ Prosocial } & 6 years $(\mathrm{N}=9)$ & $1.25(1.50)$ & $2.00(2.55)$ & $3.00(2.94)$ & $2.00(2.00)$ \\
\hline & 7 years $(\mathrm{N}=13)$ & 3.67 (3.98) & $3.29(3.20)$ & $4.33(3.78)$ & $3.86(1.95)$ \\
\hline & 8 years $(\mathrm{N}=21)$ & $4.90(3.70)$ & $4.64(2.87)$ & $4.90(3.93)$ & $3.00(2.86)$ \\
\hline & 9 years $(\mathrm{N}=2)$ & $1.00(.00)$ & $3.00(.00)$ & $3.00(.00)$ & $3.00(.00)$ \\
\hline & Total $(\mathrm{N}=45)$ & 3.67 (3.57) & $3.63(2.92)$ & $4.29(3.52)$ & $3.04(2.39)$ \\
\hline \multirow[t]{5}{*}{ Antisocial } & 6 years $(\mathrm{N}=6)$ & $3.67(1.53)$ & $4.67(5.03)$ & $2.67(2.52)$ & $5.67(4.04)$ \\
\hline & 7 years $(\mathrm{N}=18)$ & $4.75(3.01)$ & $6.50(4.38)$ & $2.50(1.60)$ & $3.50(3.84)$ \\
\hline & 8 years $(\mathrm{N}=15)$ & $5.71(4.03)$ & $5.50(3.02)$ & $6.29(4.50)$ & $3.13(3.27)$ \\
\hline & 9 years $(\mathrm{N}=9)$ & $7.67(4.04)$ & $1.83(1.72)$ & $3.33(2.89)$ & $1.67(1.75)$ \\
\hline & Total $(\mathrm{N}=48)$ & $5.33(3.37)$ & $4.96(3.86)$ & $3.90(3.39)$ & $3.22(3.33)$ \\
\hline
\end{tabular}


To highlight the effect of different types of cartoons on the prosocial behavior of children (altruism) we have used ANOVA analysis method, the results indicating a general statistically insignificant time effect $[F(1,116)=2.175, p=0.143, \eta 2=0.018]$ and also an insignificant time effect depending on subjects gender, results indicating $[F$ $(1,116)=0.068, p=0.795, \eta 2=0.001]$. Effect of time depending on child age was also insignificat statistically $[F(1,116)=2.720, p=0.615, \eta 2=0.015]$. For time depending on media type the results recorded a proximal $p$ value but still insignificant $[F(1,116)=$ $13.068 p=0.060, \eta 2=0.047]$.

Table 3 - Results of the analyses of variance

\begin{tabular}{rcccccc}
\hline & $d f$ & Type III SS & MS & $F$ & $p$ & $\eta 2$ \\
\hline Within-group effects & & & & & & \\
\hline Time & 1 & 9.838 & 9.838 & 2.175 & .143 & .018 \\
Time * Gender & 1 & .307 & .307 & .068 & .795 & .001 \\
Time * Child age & 3 & 16.388 & 2.720 & .601 & .615 & .015 \\
Time * Media type & 2 & 26.137 & 13.068 & 2.889 & .060 & .047 \\
Error (within) & 116 & & & & & \\
Gender & 1 & 6.103 & 6.103 & .693 & .407 & .006 \\
Child age & 3 & 93.947 & 31.316 & 3.555 & .017 & .084 \\
Media type & 2 & 18.334 & 9.167 & 1.041 & .356 & .018 \\
Between-group effects & & & & & & .018 \\
Gender * Child age & 3 & 38.653 & 12.884 & 1.463 & .228 & .036 \\
Gender * Media type & 2 & 1.817 & .908 & .103 & .902 & .002 \\
Child age * Media type & 6 & 40.101 & 6.683 & .759 & .604 & .038 \\
Gender * Child age * Media & 6 & 28.081 & 4.680 & .531 & .783 & .027 \\
type & & & & & & \\
Error (between) & 116 & & & & & \\
\hline
\end{tabular}

Regarding the donation volume, the pairwise analysis, with Sidak correction, didn't indicated a significant effect for the multiple comparison nor in the prosocial group nor for the antisocial group. Compared to the neutral group, the group exposed to prosocial cartoon indicated $M=-0.21$, the standard error $(S E)=0.619, p=0.982,95 \% C l=[-1.71$; 1.29 ] and the group exposed to antisocial cartoon indicated mean difference $M=-0.90$, the standard error $(S E)=0.609, p=0.371,95 \% C l=[-2.37 ; 0.58]$.

Post hoc analysis revealed for child age insignificant statistically effect for all ages except for the comparison between 6 years old and 8 years old where it has been recorded a mean difference $M=-2.30$, the standard error $(S E)=0.717, p=0.010,95 \% C l$ $=[-4.22 ;-0.38]$. 


\section{Discussion}

This study aimed to evaluate the prosocial behavior of children (specifically the altruism component) under the influence of different types of cartoons, and the evaluation is made through an act of donation to an unknown child whose situation and name has been presented to the children. The prosocial behavior targeted, altruism, was defined as an act devoid of personal benefits for the benefit of another person (Feigin et al., 2014). Research indicates that after exposure to different types of media, subjects may be influenced negatively (Friedrich \& Stein, 1973) or positively (Poulos et al., 1975; Collins \& Getz, 1976), including altruism (Wilson, 2008), children being in certain conditions under the influence of media messages from a very young age (Kaiser Family Foundation, 2006). Teachman and Orme (1981) highlighted the effect of cartoons on children (8-10 years) on prosocial behavior (altruism) manifested by donation, the antisocial cartoons having an inhibitory effect..

The hypothesis that children who will watch prosocial cartoons will have increased altruism, proving a higher volume of donations compared to those who watched antisocial cartoons has not been confirmed, the averages and standard deviations being approximately unchanged, pairwise analysis indicating no significant effect for the prosocial group. The second hypothesis that children who watch antisocial cartoons will have lower altruism proving a lower volume of donations compared to those who watched prosocial cartoons has not been statistically confirmed either. The experiment analyzed the effect of the cartoon and the gender of the subjects, the results indicating that there is no general significant difference between boys and girls, nor for the subject's age. However, there has been found a statistically significant difference for the age of 8 years old, children within this age category recording a higher volume of donation compared with those of 6 years old.

Our results recorded no significant effects of prosocial cartoons on children's altruism, similar to Teachman and Orme (1981). We have also recorded no gender effect, just as Teachman and Orme also found no significant gender influence. With regard to antisocial cartoon effects, we have recorded no significant influence whereas Teachman and Orme found a statistically significant inhibitory effect for this media type, recording a lower volume of donation. We suggest that the results should be carefully interpreted as the research paradigm has suffered minor changes and thus, we recorded a similar effect (no effect) for prosocial cartoons, whereas for antisocial cartoons we have recorded a different effect (also no effect), unlike Teachman and Orme who have recorded a statistically significant effect for antisocial cartoon. With regard to age, Teachman and Orme give no specific details, our general data being similar to Shing (1988) results who also found no age influence on altruistic behavior after exposer to cartoons. However, our data record a significant increase of donations for children age 8 years old compared to those of 6 years old.

In order to interpret the results, it was considered necessary to provide explanations due to 3 specific elements. 1) ANOVA analysis of variance indicated a proximal $p$-value 
but still insignificant $[F(1,116)=13.068 p=0.060, \eta 2=0.047] ; 2)$ the average donation for the antisocial group was initially $M=5.13$ golden coins $(S D=3.61$ ) reaching $M=3.52$ golden coins $(S D=3.33)$ in the post-intervention stage and the fact that 3$)$ in the initial stage (pre-exposure) we have a large number of extreme donations for 2 of the experimental groups (neutral and antisocial group).

Given the data presented above, we consider that the best way to interpret this data is due to the presence of a moderating factor (a confounding variable) and not necessarily due to the cartoons (Sava, 2013, p. 149), the confounded variable considered is "moral licensing" and with its direct and reverse effect. We consider that in this way, it is possible that a data prejudice has occurred through the intervention of a possible moderating factor. The concept was brought to attention by Monin and Miller (2001), and takes into account the fact that a person is able to have behaviors of dubious morality as a result of a first value / moral behavior. This valuable behavior is one according to one's own or social standards and becomes the reference point for the second behavior. The basic idea is that after a first act, after engaging in good deeds (act no. 1), for the benefit of others or without prejudice, the subject ends up feeling morally safe, in act number 2 (the second instance), and because he feels morally safe because of a good act that he has already done, the subject affords to express prejudices or different kinds of negative behaviors (Cascio \& Plant, 2015).

The "moral licensing" effect has been of interest to researchers in different behaviors, and the results are indicating a "moral disinhibition" effect due to the presence of a variable that influences the outcome. The effect was observed in the act of donation in which the subject, motivated by self-interest, is permitting himself to become selfish, reducing the volume of donation (Merritt et al., 2010) or expressing different kinds of prejudices (Kouchaki, 2011), for example regarding racist attitudes (Mann \& Kawakami, 2012). This behavior can manifest even in the concrete absence of an act of high morality, but only in the (own) evocation of the fact that he is a good person (Sachdeva et al., 2009), regardless of whether the good deed was determined from the outside or inside (Clot et al., 2011). The moral licensing effect and the studies regarding it are under certain limits (Blanken et al., 2015). This approach should be carefully taken into consideration with regard to children because most of the studies have used adult subjects. We suggest that studies like Miller, Brickman, and Bolen (Miller et al.,1975 cf. Merrit et al., 2010) who have taken into consideration the effect of labeling upon the moral licensing for children, are good support in order to suggest that moral licensing effect might have been activated, also because this theory seems to suggest best the effect and also because of the following issues listed below.

Because of this issue, we have analyzed the volume of donations made by each subject, as per group to which it was attributed in the pre-exposure stage (donation 1). The results indicated that there are two extreme values that belong to the neutral group and the antisocial group. A large number of subjects from the neutral group (11) refused to make any kind of donation ( 0 golden coins offered), eliminating any possibility to 
reduce the donation volume. Within the group that was offered the antisocial cartoon, a large number of subjects (13) registered the maximum possible donation (10 golden coins), eliminating any possibility to increase the donation volume.

The present situation seems to be best explained by the "moral licensing" effect and its reverse, research indicating that the effect may be on both groups, the second behavior being compensatory for the first, leading to two opposite effect: "moral self-licensing" and "moral cleansing". "Moral cleansing" is also an effect presented in the research work of Branas-Garza et al. (2013). Bivariate analysis of the data indicates the possible existence of the licensing effect of morality and the fact that the calculated Pearson correlation indices show a negative association between the money initially offered and the volume of donation earned, $r=-0.534, p<0.001$, and a positive association between the money offered post-intervention and the volume of the donation gained, $r=0.372, p<0.001$, where the volume of the final donation is the difference between the volume of postintervention and pre-intervention donation. We conclude thus that present results might be recorded due to the existence of a moderating factor (moral licensing), this being argued by the distribution of the volume of donations and the correlation scores, further research having the possibility of doing best to eliminate this moderating factor.

\section{Current limits and future study directions}

Built according to the model of Teachman and Orme (1981), with the improvements already mentioned, this study has the limit of contamination risk (Sava, 2013, p. 115, Torgerson, 2001). This limit might have occurred due to the fact that the experiment took place on several days, enough time for the subjects to discuss the components of the experiment. We have asked children not to talk during the experimental sessions, and the teachers have assured us of their help, limiting as much as possible discussions between children during all school days. We admit that small chats might have occurred and that might have a possible influence on the results. Another limitation of the present study is the duration of exposure to cartoons, 5 minutes and 23 seconds being a relatively short time to obtain a modified behavior, especially if we take into account the fact that in order to measure altruism, it is important to empathize with the subject or a specific cause. Regarding the exposure time limit, it should be noted that many participants in to present experiment spent 30 - 60 minutes daily in front of the cartoons (cf. collected data), which is much more than the exposure time in the present experiment.

Another limitation of the study might be given by the evaluator, whose presence might have an influence upon the subjects. This possible limitation is a real one, even though the results do not indicate an increased volume as might have been expected because of the presence of an adult. The cartoon used must be introduced as another possible limitation, limitation justified by the fact that in our current study, for ethical reasons, we have applied a careful selection especially for antisocial cartoon, not to harm subjects' minds. 
This research has an implicit limit when comparing it with Teachman and Orme experiment, the paradigm being slightly modified. If the results are interpreted only based on the present data, then this limit is not applied, but if compared with Teachman and Orme study, then we consider properly mentioning this limit because of issues listed above regarding research paradigm.

Last but not least, we consider that the main limitation considered for this study is given by the possibility of having a moderating factor: moral licensing. We believe that this is the main limit that future research should take into consideration regarding cartoons' prosocial effect.

It becomes more and more difficult to "navigate" in to the world of the 21st century due to hard times and also due to the fact that our life "will become more and more interconnected with the media" (Hogan \& Strassburger, 2008). We consider that in this new climate, the attention of parents, teachers, and researchers must be directed to the "new media" (including social media, smartphones, and tablets) because it becomes a dominant force in children's lives (Strassburger \& Hogan, 2013). The media universe has a good potential for sharing ideas, connecting people, and other benefits. They are indeed a portal for communication and entertainment if properly used by encouraging healthy use and offering good protection for small users (O'Keeffe \& Clarke Pearson, 2011).

Finally, the need for more research in the field remains both in order to provide a scientifically substantiated answer to the extent of the effect and to answer the question of the Federal Communications Commission (FCC), which stated that television programs are indeed part of the educational program. The question that we have to answer even in our present times is what kind of teaching does it offer (?) (Liebert et al., 1973). Future research will be able to carry out research work through the best possible control of variables based on the entire literature.

\section{References}

Angerer, S., Glätzle-Rützler, D., Lergetporer, P., \& Sutter, M. (2015). Donations, risk attitudes and time preferences: A study on altruism in primary school children. Journal of Economic Behavior \& Organization, 115, 67-74. doi:10.1016/j.jebo.2014.10.007

Baillargeon R. H., Morisset A., Keenan, K., Normand, C. L., Jeyaganth, S., Boivin, M. \& Tremblay, R. E. (2011). The Development of Prosocial Behaviors in Young Children: A Prospective Population-Based Cohort Study, The Journal of Genetic Psychology, 172, 221-251, doi: 10.1080/00221325.2010.533719

Batson, C. D., Duncan, B. D., Ackerman, P., Buckley, T., \& Birch, K. (1981). Is empathic emotion a source of altruistic motivation? Journal of Personality and Social Psychology, 40(2), 290-302. http://dx.doi.org/10.1037/0022-3514.40.2.290

Beilin, H. (2013). The development of prosocial behavior. Academic Press.

Beutel, A. M. \& Johnson, M. K. (2004). Gender and prosocial values during adolescence: a research note. Sociological Quarterly, 45: 379-393. doi:10.1111/j.1533-8525.2004.tb00017.x

Björkqvist, K., \& Österman, K. (2001). At What Age Do Children Learn to Discriminate between Act and Actor? Perceptual and Motor Skills, 92(1), 171-176. https://doi.org/10.2466/pms.2001.92.1.171

Blanken, I., Van de Ven, N., \& Zeelenberg, M. (2015). A meta-analytic review of moral licensing. Personality and Social Psychology Bulletin, 41(4), 540-558. http://dx.doi.org/10.1177/0146167215572134 
Brocas, I., Carrillo, J. D., \& Kodaverdian, N. (2017). Altruism and strategic giving in children and adolescents., CEPR Discussion Paper No. DP12288.

Carlo, G., McGinley, M., Hayes, R., Batenhorst, C., \& Wilkinson, J. (2007). Parenting Styles or Practices? Parenting, Sympathy, and Prosocial Behaviors Among Adolescents. The Journal of Genetic Psychology, 168(2), 147-176. doi:10.3200/gntp.168.2.147-176.

Carlo, G., Mestre, M. V., Samper, P., Tur, A., \& Armenta, B. E. (2010). Feelings or cognitions? Moral cognitions and emotions as longitudinal predictors of prosocial and aggressive behaviors. Personality and Individual Differences, 48(8), 872-877. doi:10.1016/j.paid.2010.02.010.

Cascio, J. \& Plant, A. (2015). Prospective moral licensing: Does anticipating doing good later allow you to be bad now? Journal of Experimental Social Psychology. 56. 110-116. 10.1016/j.jesp.2014.09.009.

Clot, S., Grolleau, G., \& Ibanez, L. (2011). Do Good Deeds Make Bad People?. European Journal of Law and Economics. 10.1007/s10657-014-9441-4.

Collins, W. A., \& Getz, S. K. (1976). Children's social responses following modeled reactions to provocation: Prosocial effects of a television drama. Journal of Personality, 44, 488-500.

Downs, A. C. (1990). Children's Judgments of Televised Events: The Real versus Pretend Distinction. Perceptual and Motor Skills, 70(3), 779-782. https://doi.org/10.2466/pms.1990.70.3.779

Eisenberg, N. (1983). The socialization and development of empathy and prosocial behavior. USA: Arizona State University.

Eisenberg, N., Eggum-Wilkens, N. D., \& Spinrad, T. L. (2015). The development of prosocial behavior. in D. A. Schroeder \& W. G. Graziano (Eds.), Oxford handbook of prosocial behavior (pp. 114-136). New York, NY: Oxford University Press.

Eisenberg, N., \& Mussen, P. H. (1989). The roots of prosocial behavior in children. Cambridge University Press.

Ellis, G. T., \& Sekyra III, F. (1972). The Effect of Aggressive Cartoons on the Behavior of First Grade Children. The Journal of Psychology, 81:1, 37-43, DOI: 10.1080/00223980.1972.9923785

Ergün, S. (2012). The influence of violent T.V. cartoons watched by school children in Turkey. Acta Paulista de Enfermagem, 25(spe2), 134-139. doi:10.1590/s0103-21002012000900021

Evans, A. M., Athenstaedt, U., \& Krueger, J. I. (2013). The development of trust and altruism during childhood. Journal of Economic Psychology, 36, 82-95. doi:10.1016/j.joep.2013.02.010

Fehr, E., Bernhard, H., \& Rockenbach, B. (2008). Egalitarianism in young children. Nature, 454(7208), 1079-1083. doi:10.1038/nature07155

Feigin, S., Owens, G. and Goodyear-Smith, F. (2014). Theories of human altruism: a systematic review. Annals of Neuroscience and Psychology, 1:1. Retrieved from http://www.vipoa.org/neuropsychol.

Forge, K. L., \& Phemister, S. (1987). The effect of prosocial cartoons on preschool children. Child Study Journal, 17(2), 83-88.

Foulkes, L., Leung, J. T., Fuhrmann, D., Knoll, L. J., \& Blakemore, S. J. (2018). Age differences in the prosocial influence effect. Developmental science, 21(6), e12666. doi:10.1111/desc.12666

Friedrich, L. K., \& Stein, A. H. (1973). Aggressive and prosocial television programs and the natural behavior of children. Monographs of the Society for Research in Child Development, 38 (4), 1-64.

Frydman, M. (1999). Television, aggressiveness and violence. International journal of adolescent medicine and health, 11(3-4), 335-344. doi:10.1515/ijamh.1999.11.3-4.335

Hapkiewicz, W. G., \&. Roden, A. H .(1971). The effect of aggressive cartoons on children's interpersonal play. Child Development 42(5): 1583-1585.

Hoffman, M. L. (1982). Development of prosocial motivation: Empathy and guilt. in N. Eisenberg (Ed.), The development of prosocial behavior (pp. 281-313). New York: Academic Press.

Hogan, M. J., \& Strasburger, V. C. (2008). Media and prosocial behavior in children and adolescents. in: Nucci L, Narvaez D, (Eds). Handbook of Moral and Character Education. Mahwah, NJ: Lawrence Erlbaum:537-553. 
Israely, Y., \& Guttmann, J. (1983). Children's Sharing Behavior as a Function of Exposure to Puppet-Show and Story Models. The Journal of Genetic Psychology, 142(2), 311-312. doi:10.1080/00221325.1983.10533522

Kaiser Family Foundation (2006). The media family: Electronic media in the lives of infants, toddlers, preschoolers, and their parents. Menlo Park, CA: Author.

Kogut, T. (2012). Knowing what I should, doing what I want: From selfishness to inequity aversion in young children's sharing behavior. Journal of Economic Psychology, 33(1), 226-236. doi:10.1016/j.joep.2011.10.003

Kouchaki, M. (2011). Vicarious moral licensing: The influence of others' past moral actions on moral behavior. Journal of Personality and Social Psychology, 101(4), 702-715. http://dx.doi.org/10.1037/a0024552

Liebert, R. M., Neale, J. M., \& Davidson, E. S. (1973). The early window: Effects of television on children and youth. New York: Permagon Press in Nucci, L. (Ed.) \& Narvaez, D. (Ed.). (2014). Handbook of Moral and Character Education. New York: Routledge, https://doi.org/10.4324/9780203114896

Lozada, M., D'Adamo, P., \& Carro, N. (2014). Plasticity of altruistic behavior in children. Journal of Moral Education, 43(1), 75-88. doi:10.1080/03057240.2013.878244

Madsen, E. A., Tunney, R. J., Fieldman, G., Plotkin, H. C., Dunbar, R. I. M., Richardson, J.-M., \& McFarland, D. (2007). Kinship and altruism: A cross-cultural experimental study. British Journal of Psychology, 98(2), 339-359. doi:10.1348/000712606×129213

Mann, N. H., \& Kawakami, K. (2012). The long, steep path to equality: Progressing on egalitarian goals. Journal of Experimental Psychology: General, 141(1), 187-197. http://dx.doi.org/10.1037/a0025602

Merritt, A. C., Effron, D. A., \& Monin, B. (2010). Moral self-licensing: When being good frees us to be bad. Social and Personality Psychology Compass, 4(5), 344-357. http://dx.doi.org/10.1111/j.17519004.2010.00263.x

Monin, B., \& Miller, D. T. (2001). Moral credentials and the expression of prejudice. Journal of Personality and Social Psychology, 81(1), 33-43. http://dx.doi.org/10.1037/00223514.81.1.33

O'Keeffe, G. S., \& Clarke-Pearson, K. (2011). The Impact of Social Media on Children, Adolescents, and Families. Pediatrics, 127(4), 800-804. doi:10.1542/peds.2011-0054

Peterson, L. (1983). Influence of age, task competence, and responsibility focus on children's altruism. Developmental Psychology, 19(1), 141-148.

Poulos, R. W., Rubinstein, E. A., \& Liebert, R. M. (1975). Positive social learning. Journal of Communication, 25, 90-97.

Rushton, J. P. (1975). Generosity in children: Immediate and long-term effects of modeling, preaching, and moral judgment. Journal of Personality and Social Psychology, 31(3), 459-466. http://dx.doi.org/10.1037/h0076466

Rushton, J. P. (1976). Socialization and the altruistic behavior of children. Psychological Bulletin, 83(5), 898-913. http://dx.doi.org/10.1037/0033-2909.83.5.898

Rushton, J. P., \& Teachman, G. (1978). The effects of positive reinforcement, attributions, and punishment on model induced altruism in children. Personality and Social Psychology Bulkin, 4, 322-325.

Ruston, J. P., \& Wiener, J. (1975). Altruism and cognitive development in children. British Journal of Social and Clinical Psychology, 14, 341-3

Sachdeva, S., Iliev, R.I., \& Medin, D.L. (2009). Sinning saints and saintly sinners: the paradox of moral selfregulation. Psychological science, 20 4, 523-8.

Sava, F. A. (2013). Psihologia validată științific. Ghid practic de cercetare în psihologie [Evidence based psychology. Practical guide for research in psychology]. Iași, Romania: Editura Polirom.

Seligman, M. E. P., \& Csikszentmihalyi, M. (2000). Positive psychology: An introduction. American Psychologist, 55(1), 5-14.

Shing, C. W. (1988). The Impact of Prosocial T.V. Cartoons. The Chinese University of Hong Kong. 
Skarin, K., \& Moely, B. (1976). Altruistic Behavior: An Analysis of Age and Sex Differences. Child Development, 47(4), 1159-1165. doi:10.2307/1128455

Spinrad, T. L., \& Eisenberg, N. (2009). Empathy, prosocial behavior, and positive development in schools in R. Gilman, E. S. Huebner, \& M. J. Furlong (Eds.), Handbook of positive psychology in schools (pp. 119129). New York, NY, U.S.: Routledge/Taylor \& Francis Group.

SPSS (2017). Statistical package for the social sciences, version 25 [computer program]. Chicago, IL: SPSS Inc.

Staub, E., \& Vollhardt, J. (2008). Altruism born of suffering: The roots of caring and helping after victimization and other trauma. American Journal of Orthopsychiatry, 78(3), 267-280. doi:10.1037/a0014223

Strasburger, V., \& Hogan, M. (2013). Children, Adolescents, and the Media. Pediatrics. 132. 958-961. 10.1542/peds.2013-2656.

Teachman, G., \& Orme, M. (1981). Effects of aggressive and prosocial film material on altruistic behavior of children. Psychological Reports, 48(3), 699-702. http://dx.doi.org/10.2466/pr0.1981.48.3.699

Torgerson, D. J. (2001). Contamination in trials: is cluster randomisation the answer? BMJ (Clinical research ed.), 322(7282), 355-357. doi:10.1136/bmj.322.7282.355

Underwood, B., \& Moore, B. (1982). Perspective-taking and altruism. Psychological Bulletin, 91, 143-173

Weaver, A. J., Jensen, J. D., Martins, N., Hurley, R. J., \& Wilson B. J. (2011) Liking Violence and Action: An Examination of Gender Differences in Children's Processing of Animated Content, Media Psychology, 14:1, 49-70, DOI: $10.1080 / 15213269.2010 .547829$.

Wilson, B. J. (2008). Media and 'Children's Aggression, Fear, and Altruism. The Future of Children, 18(1), 87-118. doi:10.1353/foc. 0.0005

Yarrow, M.R., Scott, P.M., \& Waxler, C.Z., (1973). Learning concern for others. Developmental Psychology, 8, 240-260.

Zarbatany, L., Hartmann, D., \& Gelfand, D. (1985). Why Does Children's Generosity Increase with Age: Susceptibility to Experimenter Influence or Altruism? Child Development, 56(3), 746-756. doi:10.2307/1129763. 